\title{
A multifunctional supramolecular vesicle based on complex of cystamine dihydrochloride capped pillar[5]arene and galactose derivative for targeted drug delivery
}

This article was published in the following Dove Press journal:

International Journal of Nanomedicine

\author{
Yuchao Lu ${ }^{1,2, *}$ \\ Chenxi Hou',* \\ Jingli Ren' \\ Kui Yang' \\ Yincheng Chang' \\ Yuxin Pei ${ }^{1}$ \\ Hai Dong ${ }^{3}$ \\ Zhichao Pei ${ }^{1}$ \\ 'Shaanxi Key Laboratory of Natural \\ Products \& Chemical Biology, College of \\ Chemistry and Pharmacy, Northwest \\ A\&F University, Yangling, Shaanxi 712100 , \\ People's Republic of China; ${ }^{2}$ Analysis \\ Center of College of Science \& \\ Technology, Hebei Agricultural \\ University, Huanghua, Hebei 06I 100, \\ People's Republic of China; ${ }^{3}$ School of \\ Chemistry \& Chemical Engineering, \\ Huazhong University of Science \& \\ Technology, Wuhan, Hubei 430074, \\ People's Republic of China \\ *These authors contributed equally to \\ this work
}

Correspondence: Hai Dong

School of Chemistry \& Chemical

Engineering, Huazhong University of Science \& Technology, Wuhan, Hubei 430074, People's Republic of China

Tel +86 2787793243

Fax +86 2787793242

Email hdong@mail.hust.edu.cn

Zhichao Pei

Shaanxi Key Laboratory of Natural

Products \& Chemical Biology, College of Chemistry and Pharmacy, Northwest A\&F

University, Yangling, Shaanxi 7/2100,

People's Republic of China

Tel +86 298709 II 96

Fax +862987092769

Email peizc@nwafu.edu.cn
Background: Supramolecular vesicles are a novel class of nanocarriers that have great potential in biomedicine.

Methods: A multifunctional supramolecular vesicle (CAAP5G) based on the complex of CAAP5 and galactose derivative $(\mathrm{G})$ assembled via host-guest interaction was constructed.

Results: Using Human embryonic kidney T (293T) cells as experimental models, the cytotoxic effects of CAAP5G was investigated to $0-50 \mu \mathrm{mol} / \mathrm{L}$ for $24 \mathrm{~h}$. Notably, the CAAP5G vesicles revealed low-toxicity to $293 \mathrm{~T}$ cells, it was critical to designing drug nano-carriers. Simultaneously, we have evaluated doxorubicin hydrochloride (DOX)-loaded CAAP5G vesicles anticancer efficiency, where DOX-loaded CAAP5G vesicles and free DOX incubated with Human hepatocellular carcinoma cancer cell (HpeG2 cells) and 293T cells for $24 \mathrm{~h}, 48 \mathrm{~h}, 72 \mathrm{~h}$. It turned out that CAAP5G vesicles encapsulated anticancer drug (DOX) could decrease DOX side-effect on 293T cells and increase DOX anticancer efficiency. More importantly, the cysteamine as an adjuvant chemotherapy drug was released from CAAP5G vesicles in HepG2 cells where a higher GSH concentration exists. The adjuvant chemotherapy efficiency was evaluated, where free DOX and DOX-loaded CAAP5G vesicles incubated with DOX-resistance HepG2 cells (HepG2-ADR cells) for 24, $48,72 \mathrm{~h}$, respectively.

Conclusion: The results revealed that the DOX encapsulated by CAAP5G vesicles could enhance the cytotoxicity of DOX and provide insights for designing advanced nano-carriers toward adjuvant chemotherapies.

Keywords: supramolecular vesicles, cysteamine, responsive, adjuvant chemotherapies, targeted drug delivery

\section{Introduction}

Drug resistance of cancer cells and side effects to normal cells are major problems in cancer chemotherapy. ${ }^{1-3}$ Nano-carriers (NC) are one of the most widely explored drug carriers in biomedicine with its distinctive properties. ${ }^{4,5}$ Especially, targeted and stimuli-responsive nano-carriers (TSNC) can target cancer cells, ${ }^{6-9}$ achieve a rapid release in the specific tumor microenvironments, enhance cytotoxicity and reduce adverse effect via new concepts or strategies based on nanotechnology. ${ }^{10-13}$ Vesicles have been one of the most popular TSNC due to their unique cavity that have the potential to encapsulate and controllably release drugs in response to 
specific stimuli. ${ }^{14-16}$ Among them, supramolecular vesicles from amphiphilic supra-molecules via host-guest complexation, especially with targeted and stimuli-responsive units, are very important in the application of biotechnology and biomedicine. ${ }^{17-20}$ Therefore, the construction of targeted and stimuli-responsive vesicles from multifunctional amphiphilic supra-molecule based on hostguest interaction between macrocyclic host molecule and guest molecule is of particular interest and importance in the progress of stimuli-responsive systems for targeted drug delivery.

Pillar[n]arenes, a new class of macrocyclic host molecule, have received much attention in supramolecular chemistry. ${ }^{21-26}$ Due to their intrinsic symmetrical and rigid structure, accessible modification and excellent properties in host-guest chemistry, pillar[n]arenes have been widely used to construct various interesting supramolecular vesicles for TSNC. ${ }^{27-31}$ For example, our group developed two types of multifunctional supramolecular vesicles, by using ferrocene or tryptophan capped pillar[5]arene, which exhibited good responsiveness and significantly enhanced the cytotoxicity of DOX. ${ }^{32,33}$

The cystamine dihydrochloride (CA), an important pharmaceutical intermediate that contained a disulfide bond (sensitive to GSH) and amino groups (sensitive to $\mathrm{pH}$ ), was investigated. ${ }^{34-36}$ Most importantly, CA can produce the drug cysteamine in the presence of GSH for adjuvant chemotherapy. ${ }^{37}$ Previous studies showed that the cysteamine not only inhibited the formation of gastric ${ }^{38}$ and mammary tumors ${ }^{39}$ that were induced chemically or after irradiation, ${ }^{40,41}$ and also enhanced the cytotoxicity of DOX $^{42}$ To the best of our knowledge, CA modified pillararene for constructing a dual-responsive amphiphilic host molecule have not yet been reported. We hypothesized that synthesis of CA capping pillararene would not only lead to a GSH-pH dual responsive amphiphilic host molecule, but also the cysteamine produced by the $\mathbf{C A}$ could enhance the cytotoxicity of DOX for adjuvant chemotherapy.

In this study, a CA-capped pillar[5]arene (CAAP5) amphiphilic host molecule was first synthesized, and thereafter the multifunctional supramolecular vesicles (CAAP5G) constructed from CAAP5 and a galactose derivative guest molecule (G) based on host-guest interaction for targeted drug nanocarriers (Scheme 1), where the galactose residue on one end of $\mathbf{G}$ can act as the targeting ligand to asialoglycoprotein receptor (ASGP-R) overexpressing HepG2 cells via carbohydrate-protein interactions. ${ }^{43}$

\section{Material and methods}

\section{Instrumentation and materials}

All chemical reagents were of analytical reagent grade and used without further purification unless specified. Doxorubicin hydrochloride was purchased from Sangon Biotech. ${ }^{1}$ NMR spectra were recorded on a Bruker $500 \mathrm{MHz}$ Spectrometer, with working frequencies of $500 \mathrm{MHz}$ for ${ }^{1} \mathrm{H}$ and $125 \mathrm{MHz}$ for ${ }^{13} \mathrm{C}$ nuclei, respectively. Scanning electron microscope (SEM) images were obtained using an S-4800 instrument (Hitachi Ltd.) with an accelerating voltage of $10.0 \mathrm{kV}$. Negative-stained TEM images were recorded on an H-7650 instrument (Hitachi Ltd. $80 \mathrm{kV}$ ). Dynamic light scattering (DLS) measurements were performed on a Delsa ${ }^{\mathrm{TM}}$ Nano system (Beckman Coulter, U.S.A.). Water surface tension was recorded with a BZY-3B surface tension measurer (China). An AXIMA-CFR ${ }^{\mathrm{TM}}$ plus MALDI-TOF Mass Spectrometer (Kratos, UK) was used for mass analysis. UV-Vis spectra were recorded with a Shimadzu 1750 UVVisible spectrophotometer (Japan) at $298 \mathrm{~K}$. HepG2 cells and HepG2-ADR cells were obtained from the Type Culture Collection of the Chinese Academy of Science (Shanghai, China). 293T cells were obtained from the KeyGEN BioTECH Co. (Nanjing, China). Cell culture was carried out in an incubator with a humidified atmosphere of $5 \% \mathrm{CO}_{2}$ at $37{ }^{\circ} \mathrm{C}$.

\section{Methods}

The preparation and characterization of the vesicles $2.46 \mathrm{mg}(0.5 \mu \mathrm{mol})$ of CAAP5 was dissolved in $\mathrm{H}_{2} \mathrm{O}(0.5 \mathrm{~mL})$ and stirred for $5 \mathrm{~min}$. The solution was mixed $0.5 \mathrm{~mL} \mathbf{G}$ $(1 \mathrm{mM})$. The final mixture was ultrasonicated for $30 \mathrm{~min}$, then left to stand for $6 \mathrm{~h}$ to obtain the vesicles of CAAP5G, which were characterized by SEM, DLS, and TEM, respectively.

\section{DOX loading and release of CAAP5G vesicles}

$2.46 \mathrm{mg}(0.5 \mu \mathrm{mol})$ of CAAP5 was dissolved in $\mathrm{H}_{2} \mathrm{O}$ $(0.5 \mathrm{~mL})$ and stirred for $5 \mathrm{~min}$. To the solution were mixed $0.5 \mathrm{~mL}$ G $(1 \mu \mathrm{mol})$ and $0.58 \mathrm{mg} \operatorname{DOX}(1 \mu \mathrm{mol})$. The mixture was ultrasonicated for $30 \mathrm{~min}$ and left to stand for $6 \mathrm{~h}$, then subjected to dialysis (molecular weight cutoff $8,000-14,000)$ in distilled water. DOX-loaded vesicles were obtained when no DOX detected in the water outside the dialysis tube. ${ }^{44}$

The DOX release from DOX-loaded CAAP5G was studied at different $\mathrm{pH}$ buffer solution, with or without 


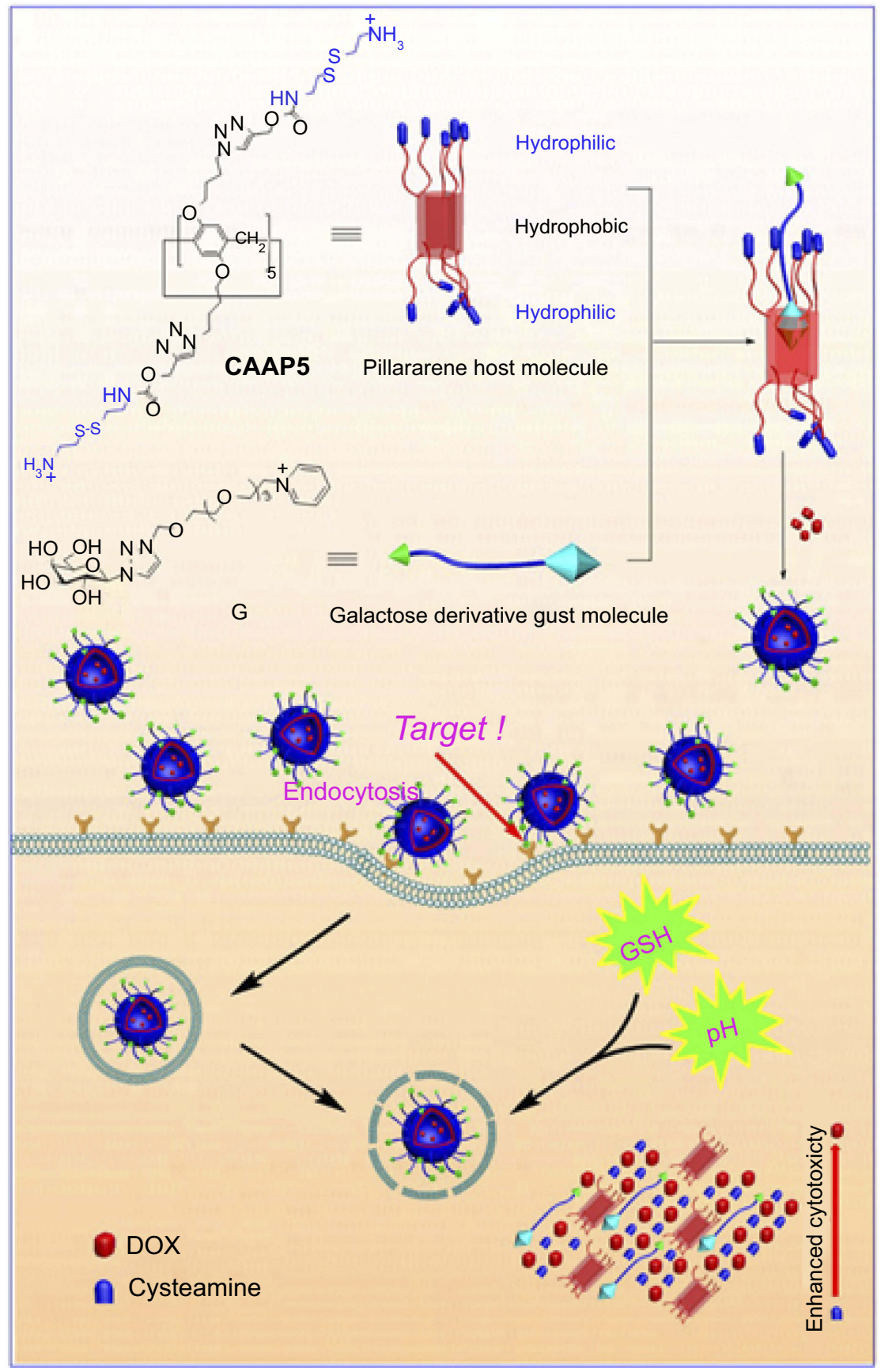

Scheme I Schematic illustration of the synthesis of CAAP5, the host-guest complexation with galactose derivatives (G), formation of vesicles (CAAP5G), and their GSH/ $\mathrm{pH}$ dual-responsive drug release.

GSH $(10 \mathrm{mM}) .1 \mathrm{~mL}$ of DOX-loaded vesicles in a dialysis bag was added into $10 \mathrm{~mL}$ of corresponding release medium at room temperature. Within specified time intervals, $0.1 \mathrm{~mL}$ of the release medium was taken out for measuring the DOX released with an Epoch microplate spectrophotometer (Biotek).

\section{Cell culture and cell viability}

HepG2 cells and HepG2-ADR cells were cultured in RPMI 1640 containing $1 \%$ penicillin-streptomycin, $10 \% \mathrm{FBS}$, in a humidified atmosphere $\left(5 \% \mathrm{CO}_{2}\right)$ at $37{ }^{\circ} \mathrm{C}$. $293 \mathrm{~T}$ cells were cultured in DMEM medium containing $1 \%$ penicillin-streptomycin, $10 \% \mathrm{FBS}$, in a humidified atmosphere $\left(5 \% \mathrm{CO}_{2}\right)$ at 
$37^{\circ} \mathrm{C}$. The relative cytotoxicity of unloaded vesicles, DOX and DOX-loaded vesicles were evaluated in vitro by MTT assay, respectively. MTT assay procedures refer to our previous work. ${ }^{44}$

\section{Results and discussion}

To acquire CAAP5, azido-pillar[5]arene H5 and alkynyl cystamine derivative $\mathbf{H 4}$ were synthesized according to a published procedure, respectively. ${ }^{45,46}$ The CAAP5 can be synthesized through $\mathrm{Cu}$-catalyzed azido-alkynyl click reaction. The synthetic details and characterization of CAAP5 and $\mathbf{G}$ can be found in the Supporting Information (Schemes S1-S3, Figures S1-S11).

The host-guest interaction of CAAP5 and $\mathbf{G}$ was investigated in $\mathrm{D}_{2} \mathrm{O}$ via the ${ }^{1} \mathrm{H}$ NMR spectroscopy. The up field chemical shifts of the pyridine protons $\left(\mathrm{H}_{1-3}\right)$ of $\mathbf{G}$ were observed due to the shielding effect of the electron-rich cavities of CAAP5 toward G (see in Figure S12). This result was consistent with that published, ${ }^{21,32,33}$ demonstrating the pyridine moiety of $\mathbf{G}$ has been successfully included into the hydrophobic cavity of CAAP5.

To construct the targeting dual-responsive supramolecular vesicles (CAAP5G) based on the CAAP5 and G host-guest interaction, an aqueous solution of CAAP5 and G was sonicated for $30 \mathrm{~min}$. We observed a clear Tyndall effect (Figure 1A right), indicating the existence of abundant nanoparticles, which were further identified by scanning electron microscopy SEM (Figure 1B). TEM image demonstrated the cavity of the vesicles, which was used to loading-drug (Figure 1C). Further analysis with DLS showed that the average diameter of the vesicles was $158 \mathrm{~nm}$ (Figure 1D). The critical aggregation concentration (CAC) was found to be $22 \mu \mathrm{M}$ by the water surface tension method (Figure S14).

In the following study, DOX was selected as a model drug to investigate the drug release behavior and encapsulation efficiency of the supramolecular vesicles. As showed in Figure 1A (left), a clear Tyndall effect was observed with DOX-loaded CAAP5G aqueous solution. DLS showed that the average diameter of the DOX-loaded CAAP5G vesicles was $203 \mathrm{~nm}$ (Figure S13), which were further identified by SEM (Figure 2A). The CAAP5G encapsulation efficiency was calculated $41 \mathrm{wt} \%$ by UVvis spectroscopy. Subsequently, the DOX-loaded CAAP5G vesicles released DOX was studied in an acidic solution ( $\mathrm{pH} 4.0$ ), neutral solution ( $\mathrm{pH} 7.4$ ), and with GSH
A

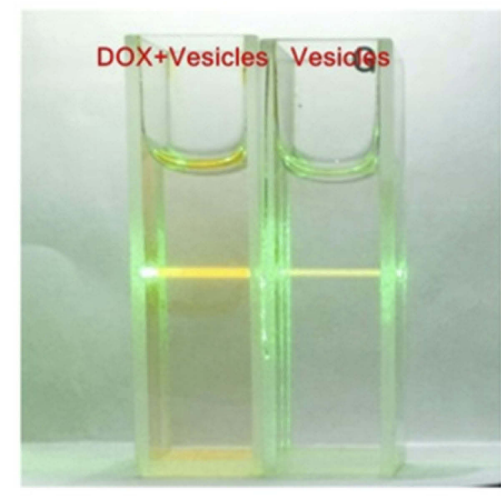

C

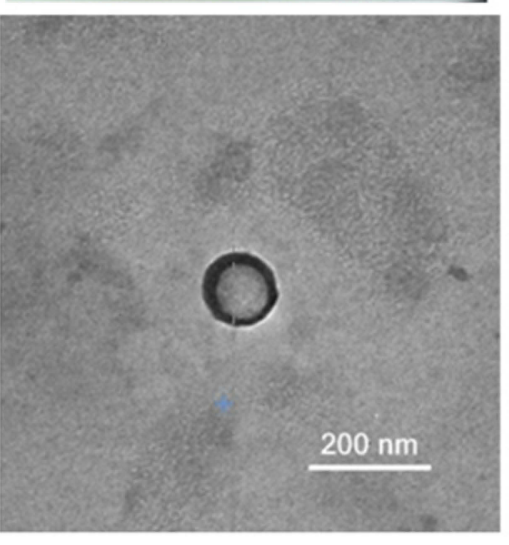

B

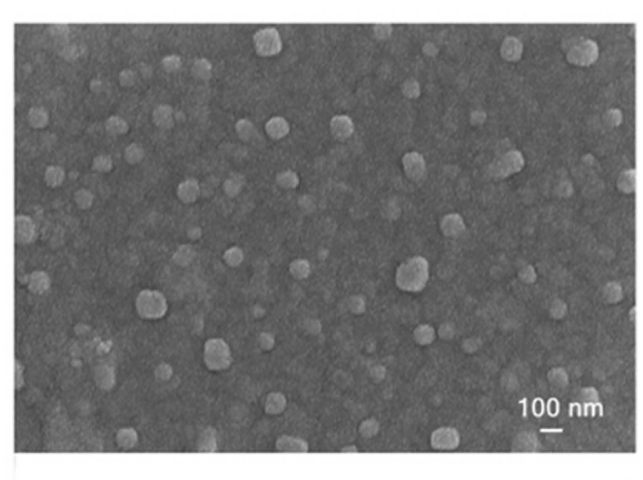

D

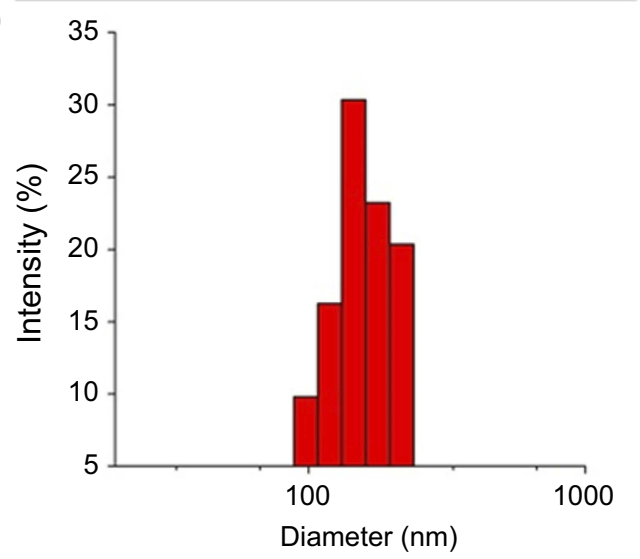

Figure I (A) Tyndall effect of CAAP5G and DOX-loaded CAAP5G; (B) SEM image of CAAP5G vesicles; (C) TEM image of CAAP5G vesicles; (D) DLS histogram of CAAP5G vesicles. 

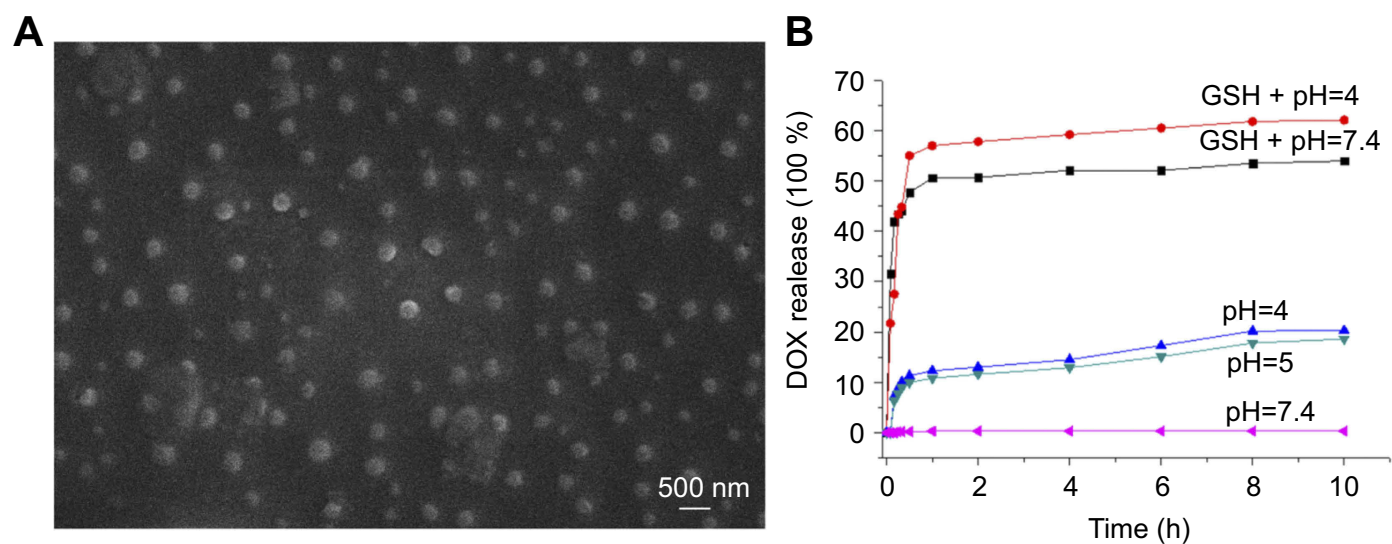

Figure 2 (A) SEM image of DOX-loaded CAAP5G vesicles; (B) DOX release profiles from DOX-loaded CAAP5G vesicles in PBS with GSH (IOmM) + pH (4.0), GSH $(10 \mathrm{mM})+\mathrm{pH}(7.4), \mathrm{pH}(4.0), \mathrm{pH}(5.0)$ and $\mathrm{pH}(7.4)(\mathrm{n}=3)$.

$(10 \mathrm{mM})$ in solution ( $\mathrm{pH} 7.0)$ and acidic solution $(\mathrm{pH} 4.0)$, respectively, mimicking the concentration of GSH in cancer cells $(1-11 \mathrm{mM})$. As indicated in Figure 2B, 20\% and $54 \%$ of DOX were released under acidic conditions $(\mathrm{pH}$ 4.0) and $10 \mathrm{mM} \mathrm{GSH}$, respectively. In the acidic buffer solutions, CAAP5 functional groups $-\mathrm{NH}_{2}$ were ionized to $-\mathrm{NH}_{3}{ }^{+}$, leading to a greater quantity of positive charges, which changed the CAAP5G hydrophilic/hydrophobic ratio and further lead to the rupture of vesicles to release drugs. As a result, the solution in the presence of GSH had a quicker release rate. By comparison, the amount of DOX release reached a maximum of $62 \%$ when cultured with
GSH $(10 \mathrm{mM})$ in solution (pH4.0), indicating that GSH and $\mathrm{pH}$ dual-responsiveness mediated efficient disassembly of DOX-loaded vesicles. These results show that DOX-loaded CAAP5G vesicles are relative stable under physiological condition and can be used for drug controllable release.

The cellular uptake of DOX-loaded vesicles was investigated by CLSM. Red fluorescence could be observed clearly in the nuclei of HepG2 cells after $4 \mathrm{~h}$ incubation with DOXloaded CAPP5G vesicles, indicating that DOX loaded by CAPP5G vesicles could enter the cancer cells (Figure 3A). To evaluate the targeting effect of CAAP5G vesicles, HepG2
A
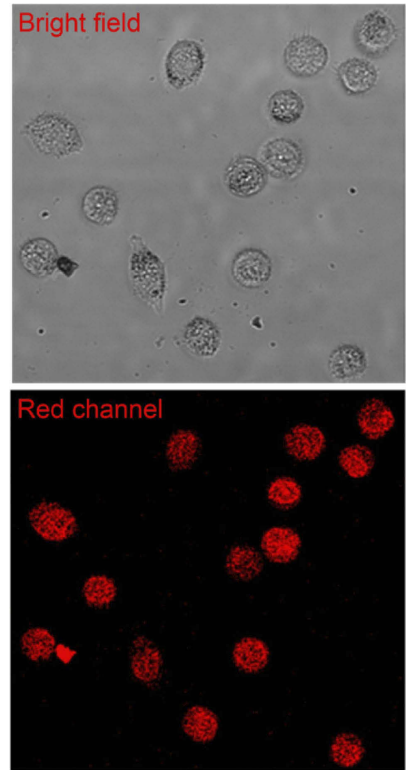
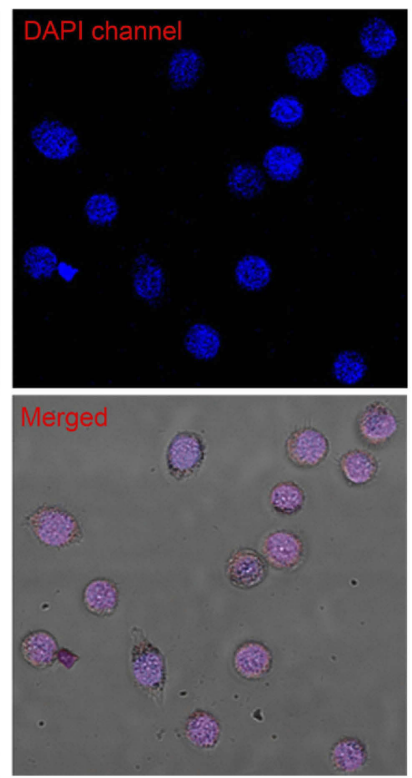

B

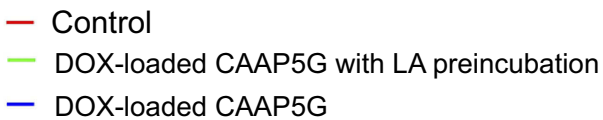

- DOX-loaded CAAP5G

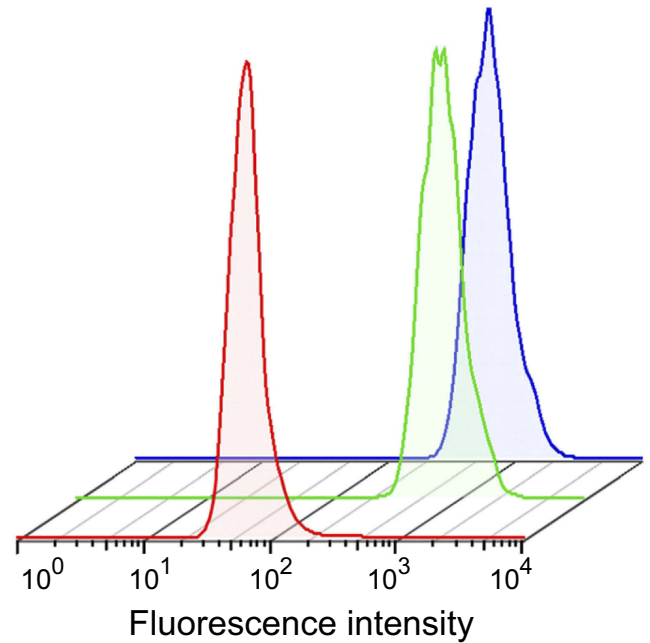

Figure 3 (A) CLSM images of HepG2 cells after being treated with DOX loaded CAAP5G vesicles for 4 h. The final concentration of DOX in the medium was $5 \mu$ M. (B) Fluorescence intensity of HepG2 cells treated with free DOX (red line), DOX-loaded CAAP5G vesicles (blue line), DOX-loaded CAAP5G after pre-incubation with lactose for $4 \mathrm{~h}$ (green line) by flow cytometry analysis, respectively. 
cells were incubated with DOX-loaded CAAP5G vesicles and free DOX at $5 \mu \mathrm{M}$ for $4 \mathrm{~h}$, respectively, where the efficiency of cellular uptake was analyzed by flow cytometry. HepG2 cells pre-cultured with lactose $(2 \mathrm{mg} / \mathrm{mL})$ for $4 \mathrm{~h}$, were used to culture with DOX-loaded CAAP5G vesicles for comparison. As showed in Figure 3B, the fluorescence intensity of HepG2 cells cultured with DOX-loaded CAAP5G vesicles (blue curve) was higher than that of DOX-loaded CAAP5G with lactose pre-incubation (green curve), indicating a higher uptake of DOX-loaded CAAP5G vesicles. The results imply that CAAP5G displays hepatoma-targeting ability. In addition, the cell toxicity of unloaded vesicles to 293 T cells are evaluated by the MTT cell survival assay. As indicated in Figure S15 (ESI $\dagger$ ), the relative cell viability of 293 T cells cultured with unloaded vesicles was over $82 \%$ in the concentrations of $50 \mu \mathrm{M}$ CAAP5G after $24 \mathrm{~h}$, showing that the vesicles had low cell toxicity to $293 \mathrm{~T}$ cells, which was essential for the design of drug nano-carriers.

The anticancer efficency of DOX-loaded CAAP5G vesicles was evaluated using MTT cell survival assay, where HpeG2 cells and 293T cells were incubated with free DOX and DOX-loaded CAAP5G vesicles for 24, 48, and $72 \mathrm{~h}$, respectively. As indicated in Figure 4A, in all three tested periods, the relative viabilities of HepG2 cells after cultured with DOX-loaded CAAP5G vesicles were visibly lower than those with free DOX. By comparison, 293 T cells showed higher relative viabilities than those with free DOX (Figure 4A). The results indicated that the encapsulation of DOX by CAAP5G vesicles could enhance the drug anticancer efficiency for HepG2 cells while effectively reduce the side effects to $293 \mathrm{~T}$ cells.
In the presence of GSH, CAAP5G vesicles can produce the cysteamine, an adjuvant chemotherapy drug, that enhances the cytotoxicity of DOX. ${ }^{42}$ To study the adjuvant chemotherapy efficiency of CAAP5G vesicles, HepG2ADR cells were cultured with free DOX and DOX-loaded CAAP5G vesicles for 24, 48, and $72 \mathrm{~h}$, respectively (Figure 5). The results showed that the relative viabilities of HepG2-ADR cells after incubation with DOX-loaded CAAP5G vesicles at all three tested time periods were visibly lower than those with free DOX. It indicated DOXloaded CAAP5G vesicles could enhance anticancer efficiency of HepG2-ADR cells comparison with free DOX, suggesting CAAP5G as a multifunctional supramolecular vesicle can be used in adjuvant chemotherapy.

\section{Conclusion}

In conclusion, novel multifunctional supramolecular vesicles (CAAP5G) based on the host-guest complexation of CAAP5 and G have been successfully constructed and the good drug-loading capability was demonstrated by drug loading experiments. Furthermore, DOX-loaded CAAP5G not only exhibited excellent dual stimuli responsiveness and rapid release of DOX in cancer cells but also possesses targeting ability to ASGP-R overexpressing HepG2 cells. Most notably, the vesicles under high concentration of GSH would release cysteamine, which could enhance the anticancer efficiency of DOX and reduce the drug resistance of cancer cells. This work provides a new idea for rational design in the construction of targeted and stimuli-responsive nanocarriers for drug delivery, which have great applications for adjuvant chemotherapy.
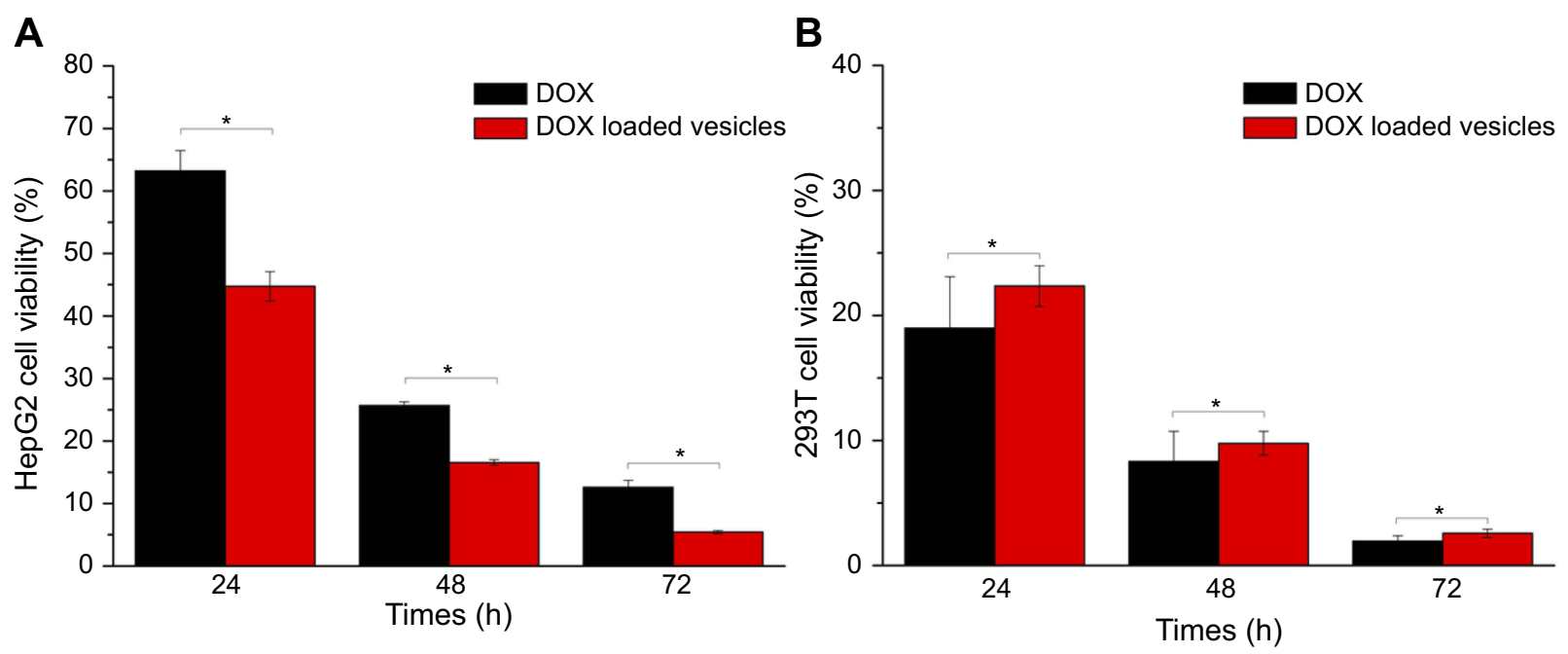

Figure 4 Comparison of DOX-loaded CAAP5G vesicles and DOX on viabilities of HepG2 cells (A) and 293T cells (B) at different time periods; the concentration of DOX was $5 \mu$ M. Statistically significant differences were observed $\left({ }^{*} p<0.05\right)$. 


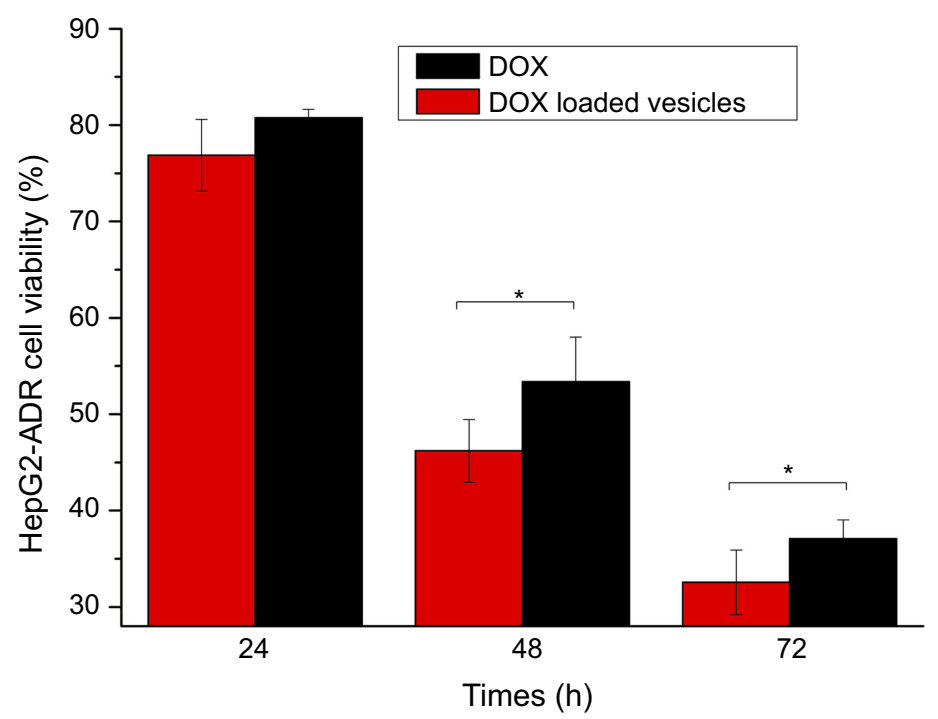

Figure 5 Comparison of DOX-loaded CAAP5G vesicles and DOX on viabilities of HepG2-ADR cells at different time periods; the concentration of DOX was $5 \mu$ M. Statistically significant differences were observed $(* p<0.05)$.

\section{Acknowledgments}

This research work was supported by the National Natural Science Foundation of China (No. 21572181 and 21772157). Specialized Research Fund for the Doctoral Program of Hebei Agricultural University (2D201712), and Science \& Technology Fund of Hebei Agricultural University (LG201811).

\section{Disclosure}

The authors report no conflicts of interest in this work.

\section{References}

1. Mousa SA, Bharali DJ. Nanotechnology-based detection and targeted therapy in cancer: nano-bioparadigms and applications. Cancers. 2011;3:2888-2903. doi:10.3390/cancers3032888

2. Shao C, Shang K, Xu HB, et al. Facile fabrication of hypericinentrapped glyconanoparticles for targeted photodynamic therapy. Int $J$ Nanomedicine. 2018;13:4319-4331. doi:10.2147/IJN S161262

3. Liu J, Huang YR, Kumar A, et al. pH-sensitive nano-systems for drug delivery in cancer therapy. Biotechnol Adv. 2014;32:693-710. doi:10.1016/j.biotechadv.2013.11.009

4. Allen TM, Cullis PR. Drug delivery systems: entering the mainstream. Science. 2004;303:1818-1822. doi:10.1126/science.1095833

5. Zhao ZL, Meng HM, Wang NN, et al. A controlled-release nanocarrier with extracellular $\mathrm{pH}$ value driven tumor targeting and translocation for drug delivery. Angew Chem Int Ed. 2013;52:7487-7491. doi:10.1002/anie.201302557

6. Wang ZH, Tian YF, Zhang H, et al. Using hyaluronic acid-functionalized $\mathrm{pH}$ stimuli-responsive mesoporous silica nanoparticles for targeted delivery to CD44-overexpressing cancer cells. Int $J$ Nanomedicine. 2016;11:6485-6497. doi:10.2147/IJN.S117184

7. Cao SP, Pei ZC, Xu YQ, Pei YX. Glyco-nanovesicles with activatable near-Infrared probes for real-time monitoring of drug release and targeted delivery. Chem Mater. 2016;28:4501-4506. doi:10.1021/acs. chemmater.6b01857
8. Kanamala M, Wilson WR, Yang M, Palmer BD, Wu Z. Mechanisms and biomaterials in $\mathrm{pH}$-responsive tumour targeted drug delivery: A review. Biomaterials. 2016;85:152-167. doi:10.1016/j.biomaterials.2016.01.061

9. Zhang Y, Wu XW, Hou CX, et al. Dual-responsive dithio-polydopamine coated porous $\mathrm{CeO}_{2}$ nanorods for targeted and synergistic drug delivery. Int J Nanomedicine. 2018;13:2161-2173. doi:10.2147/IJN. $\mathrm{S} 152002$

10. Feng QH, Zhang YY, Zhang WX, et al. Tumor-targeted and multistimuli responsive drug delivery system for near-infrared light induced chemo-phototherapy and photoacoustic tomography. Acta Biomater. 2016;38:129-142. doi:10.1016/j.actbio.2016.04.024

11. Cui W, Li J, Decher G. Self-assembled smart nanocarriers for targeted drug delivery. Adv Mater. 2016;28:1302-1311. doi:10.1002/ adma.201502479

12. Dai LL, Liu JJ, Luo Z, Li M, Cai KY. Tumor therapy: targeted drug delivery systems. J Mater Chem B. 2016;4:6758-6772. doi:10.1039/ C6TB01743F

13. Liu CQ, Chen ZW, Wang ZZ, et al. A graphitic hollow carbon nitride nanosphere as a novel photochemical internalization agent for targeted and stimuli-responsive cancer therapy. Nanoscale. 2016;8:12570-12578. doi:10.1039/c5nr07719b

14. Meng LB, Zhang WY, Li DQ, et al. pH-responsive supramolecular vesicles assembled by water-soluble pillar[5]arene and a BODIPY photosensitizer for chemo-photodynamic dual therapy. Chem Commun. 2015;51:14381-14384. doi:10.1039/C5CC05785J

15. Gao LY, Zheng B, Chen W, Schalley CA. Enzyme-responsive pillar [5]arene-based polymer-substituted amphiphiles: synthesis, selfassembly in water, and application in controlled drug release. Chem Commun. 2015;51:14901-14904. doi:10.1039/C5CC06207A

16. Chang YC, Yang K, Wei P, et al. Cationic vesicles based on amphiphilic pillar[5]arene capped with ferrocenium: a redox-responsive system for drug/siRNA co-delivery. Angew Chem Int Ed. 2014;53:13126-13130. doi:10.1002/anie.201407272

17. Yu GC, Han CY, Zhang ZB, et al. Pillar[6]arene- based photoresponsive host-guest complexation. J Am Chem Soc. 2012;134:8711-8717. doi:10.1021/ja302998q

18. Lee BS, Yip AT, Thach AV, Rodriguez AR, Deming TJ, Kamei DT. The targeted delivery of doxorubicin with transferrin-conjugated block copolypeptide vesicles. Int J Pham. 2015;496:903-911. doi:10.1016/j.ijpharm.2015.10.028 
19. Chi XD, Yu GC, Shao L, Chen JZ, Huang FH. A dual-thermoresponsive gemini-type supra-amphiphilic macromolecular [3] pseudorotaxane based on pillar[10]arene/paraquat cooperative complexation. $J$ Am Chem Soc. 2016;138:3168-3174. doi:10.1021/jacs.5b13173

20. Duan QP, Cao Y, Li Y, et al. pH-responsive supramolecular vesicles based on water-soluble pillar[6]arene and ferrocene derivative for drug delivery. J Am Chem Soc. 2013;135:10542-10549. doi:10.1021/ja405014r

21. Ogoshi T, Kanai S, Fujinami S, Yamagishi TA, Nakamoto Y. ParaBridged symmetrical pillar[5]arenes: their Lewis acid catalyzed synthesis and host-guest property. J Am Chem Soc. 2008;130:50225023. doi:10.1021/ja711260m

22. Li H, Chen DX, Sun YL, et al. Viologen-mediated assembly of and sensing with carboxylatopillar[5] arene-modified gold nanoparticles. $J$ Am Chem Soc. 2013;135:1570-1576. doi:10.1021/ja3115168

23. Chen L, Si W, Zhang L, Tang G, Li Z-T, Hou J-L. Chiral selective transmembrane transport of amino acids through artificial channels. $J$ Am Chem Soc. 2013;135:2152-2155. doi:10.1021/ja312704e

24. Yu GC, Jie KC, Huang FH. Supramolecular amphiphiles based on host-guest molecular recognition motifs. Chem Rev. 2015;115:72407303. doi: $10.1021 / \mathrm{cr} 5005315$

25. Wang YL, Ping GC, Li CJ. Efficient complexation between pillar[5] arenes and neutral guests: from host-guest chemistry to functional materials. Chem Commun. 2016;52:9858-9872. doi:10.1039/ C6CC03999E

26. Xiao TX, Zhong WW, Zhou L, et al. Artificial light-harvesting systems fabricated by supramolecular host-guest interactions. Chin Chem Lett. 2019;30:31-36. doi:10.1016/j.cclet.2018.05.034

27. Hu XB, Chen L, Si W, Yu YH, Hou JL. Pillar[5] arene decaamine: synthesis, encapsulation of very long linear diacids and formation of ion pair-stopped [2]rotaxanes. Chem Commun. 2011;47:4694-4696. doi:10.1039/c1cc10633c

28. Wang Y, Xu JF, Chen YZ, et al. Photoresponsive supramolecular selfassembly of monofunctionalized pillar[5]arene based on stiff stilbene. Chem Commun. 2014;50:7001-7003. doi:10.1039/C4CC02760D

29. Chi XD, Ji XF, Xia DY, Huang FH. A dual-responsive supra-amphiphilic polypseudorotaxane constructed from a water-soluble pillar[7] arene and an azobenzene-containing random copolymer. J Am Chem Soc. 2015;137:1440-1443. doi:10.1021/ja512978n

30. Yang K, Pei YX, Wen J, Pei ZC. Recent advances in pillar[n]arenes: synthesis and applications based on host-guest interactions. Chem Commun. 2016;52:9316-9326. doi:10.1039/C6CC03641D

31. Jiang L, Huang X, Chen D, Yan H, Li X, Du X. Supramolecular vesicles coassembled from disulfide-linked benzimidazolium amphiphiles and carboxylate-substituted pillar[6]arenes that are responsive to five stimuli. Angew Chem Int Ed. 2017;56:2655-2659. doi:10.1002/anie.201611973

32. Yang K, Chang YC, Wen J, et al. Supramolecular vesicles based on complex of trp-modified pillar[5]arene and galactose derivative for synergistic and targeted drug delivery. Chem Mater. 2016;28:19901993. doi:10.1021/acs.chemmater.6b00696
33. Chang YC, Hou CX, Ren JL, et al. Multifunctional supramolecular vesicles based on the complex of ferrocenecarboxylic acid capped pillar[5]arene and a galactose derivative for targeted drug delivery. Chem Commun. 2016;52:9578-9581. doi:10.1039/ C6CC03637F

34. Hassan W, Beuzard Y, Rosa J. Inhibition of erythrocyte sickling by cystamine, a thiol reagent. Proc Natl Acad Sci US A. 1976;73:3288-3292.

35. Aleman MM, Holle LA, Stember KG, et al. Cystamine preparations exhibit anticoagulant activity. PloS One. 2015;10:e124448. doi:10.1371/journal.pone.0124448

36. Karpuj MV, Becher MW, Springer JE, et al. Prolonged survival and decreased abnormal movements in transgenic model of huntington disease, with administration of the transglutaminase inhibitor cystamine. Nat Med. 2002;8:143-149. doi:10.1038/nm0202-143

37. Besouw M, Masereeuw R, Heuvel LVD, Levtchenko E. Cysteamine: an old drug with new potential. Drug Discov Today. 2013;18:785792. doi:10.1016/j.drudis.2013.02.003

38. Inano H, Onoda M, Suzuki K, Kobayashi H, Wakabayashi K. Inhibitory effects of WR-2721 and cysteamine on tumor initiation in mammary glands of pregnant rats by radiation. Radiat Res. 2000;153:68-74. doi:10.1667/0033-7587(2000)153[0068:ieowac]2.0. co;2

39. Tatsuta M, Iishi H, Yamamura H, Baba M, Mikuni T, Taniguchi H. Inhibitory effect of prolonged administration of cysteamine on experimental carcinogenesis in rat stomach induced by $\mathrm{N}$-methylN'-nitro-N-nitrosoguanidine. Int J Cancer. 1988;41:423-426.

40. Fujisawa T, Rubin B, Suzuki A, et al. Cysteamine suppresses invasion, metastasis and prolongs survival by inhibiting matrix metalloproteinases in a mouse model of human pancreatic cancer. PLoS One. 2012;7:e34437. doi:10.1371/journal.pone.0034437

41. Lespinasse F, Oiry J, Fatome M, et al. Radioprotection of EMT6 tumor by a new class of radioprotectors based on a pseudo-peptide cysteamine combination. Int J Radiat Oncol Biol Phys. 1985;11:1035-1038.

42. Wan XM, Zheng F, Zhang L, et al. Autophagy-mediated chemosensitization by cysteamine in cancer cells. Int $J$ Cancer. 2011;129:1087-1095. doi:10.1002/ijc.25771

43. Chen W, Zou Y, Meng FH, et al. Glyco-nanoparticles with sheddable saccharide shells: a unique and potent platform for hepatoma-targeting delivery of anticancer drugs. Biomacromolecules. 2014;15:900907. doi:10.1021/bm401749t

44. Chang YC, Lv YH, Wei P, et al. Multifunctional glycol-nanofibers: siRNA induced supermolecular assembly for codelivery In vivo. Adv Funct Mater. 2017;27:1703083. doi:10.1002/adfm.201703083

45. Zhang J, Li C, Wang Y, Zhuo RX, Zhang XZ. Controllable exploding microcapsules as drug carriers. Chem Commun. 2011;47:4457-4459. doi:10.1039/c1cc10337g

46. Yang J, Shao L, Yu GC. Construction of pillar[6]arene-based $\mathrm{CO}_{2}$ and UV dual-responsive supra-amphiphile and application in controlled self-assembly. Chem Commun. 2016;52:3211-3214. doi:10.1039/C5CC10617F

\section{Publish your work in this journal}

The International Journal of Nanomedicine is an international, peerreviewed journal focusing on the application of nanotechnology in diagnostics, therapeutics, and drug delivery systems throughout the biomedical field. This journal is indexed on PubMed Central, MedLine, CAS, SciSearch ${ }^{\circledR}$, Current Contents ${ }^{\circledR} /$ Clinical Medicine,
Journal Citation Reports/Science Edition, EMBase, Scopus and the Elsevier Bibliographic databases. The manuscript management system is completely online and includes a very quick and fair peer-review system, which is all easy to use. Visit http://www.dovepress.com/ testimonials.php to read real quotes from published authors. 